\title{
Construction of Government Ruled by Law from the Perspective of Social Governance
}

\author{
Chao Fan \\ Jiangsu Luman Law Firm, Nanjing, China \\ Email address: \\ 775809699@qq.com \\ To cite this article: \\ Chao Fan. Construction of Government Ruled by Law from the Perspective of Social Governance. International Journal of Law and Society. \\ Vol. 2, No. 4, 2019, pp. 68-72. doi: 10.11648/j.ijls.20190204.12
}

Received: October 7, 2019; Accepted: December 2, 2019; Published: December 7, 2019

\begin{abstract}
The legalization of government behavior is the key link of social governance innovation. Social governance innovation is not only the time adaptation and power accumulation at the historical level, but also the value orientation and connotation exploration at the normative level, as well as the horizon expansion and path setting at the methodological level. The systematic innovation of social governance determines that the construction of government ruled by law must focus on regulating the relations between the government and society, and the internal relations within the government by adopting the practical path of "work in concert both inside and outside, work in connection from up to down" guided by the methodological principle of "integration". The main leader of social governance is the government. The government needs to play a leading role in the realization of social governance innovation, actively introduce social forces, jointly promote the innovation of social governance system, and improve social governance capacity. To give full play to the main role of the government, it is necessary for the government to continuously improve the system construction of social governance and promote the legalization of social governance. The government under the rule of law needs not only the rule of law system, but also the rule of law culture. The government should carry out the construction of the rule of law culture for the government staff, who are the direct subjects participating in social governance, and incorporate the assessment conditions of "rule of law" into their personal career development, so as to promote the government staff to identify with the rule of law culture.
\end{abstract}

Keywords: Social Governance, Government Domination, Law-Based Government

\section{The Role of Government in Social Governance}

As an important part of national governance system and organic organization, social governance is a kind of structural system construction and policy arrangement. [1] Generally speaking, the concept of social governance is of two aspects. Firstly, it focuses on the normative meaning in which social governance is regarded as a modern way of dealing with social public affairs by endowing it with structural meaning and based on individual freedom and social standard. Different from the social domination characterized by "authority-dependence-compliance" and the social management featured by "contract-control-obedience" and "competition-management-cooperation" [2], social governance emphasizes more on realizing the multiple cooperation and co-governance between the government society and the self-governance of the society with removing the authority of the government. In this sense, the relationship between social governance social domination and social management is antagonistic. Secondly, it places emphasis on the historical significance with regarding the social governance as a process of governing society, i.e. handling the public affairs based on the specific relations between government and society, including the maintenance of social order, the regulation of social behavior, the mediation of social contradictions, the provision of social services and the guarantee of social security, etc. In this sense, social governance contains many connotations, such as social domination, social management, social services and social autonomy. In this sense, social governance contains many connotations, such as social domination, social management, social services and social autonomy. However, the primary and secondary position of these aspects in the structure of social governance system will change with the development of 
history, which determines the main body, mode of social governance and the role and responsibility of the government. As thus, different models of social governance structure have been formed.

Innovative social governance not only concerns how to develop social organizations and improve grassroots self-governance, but also involves how to correctly position the government and how to govern the society. Under the background of the single governance mode controlled by the government, it is more important for the government to find its position and re-select the governance mode than developing the society itself. Social governance must give full play to the leading role of the government, which is the basis and premise of the innovation of social governance. [3] The leading role of government refers to its function of mobilization, guidance, organization, integration and process control in social governance innovation. Specifically, this dominant role is mainly reflected in the following aspects:

First, the cultivation of social organizations. We should innovate the way of social governance, integrate social resources and promote the cultivation of social autonomy. [4] Although marketization has a huge driving force for social organization and the society itself also has the demand for organization, the conscious promotion and regulation by government is indispensable in the advance of marketization, the formation of social organization space, the improvement of the system basis of social organization activities, and the determination of the field of social self-governance. The government should strengthen the reconstruction of social organizations, properly define the boundary between the government and the society, take promoting the self-discipline and self consistent autonomy of social organizations as the main line, improve the governance structure of social organizations, cultivate and develop social organizations, and construct the social governance organization system, which are the organizational conditions for the construction of a society ruled by law. [5]

Second, the establishment of organizational system of social governance. The establishment of organizational system refers to the practical process in which the government regulates, mobilizes and guides social forces into the field of social governance. "If governance means a system of rules without the organized support of a government, who will formulate and implement these rules?"[6]Although social organization is also an important subject of social governance innovation, any spontaneous social innovation must be recognized by the government and transformed into the system so as to be legitimate, universal and durable.

Third, the process coordination of social governance. The reason why social governance emphasizes social participation lies in the heterogeneity of society itself, which makes different social strata have different views and opinions on public affairs, thus leading to the complexity and difficulty when dealing with public affairs. Participation is important, but it is only a sign of democracy, not a guarantee of problem solving. Coordination based on balance and consultation contributes to the achievement of consensus and compromise among all parties involved in social governance, which is a necessary condition for good governance. Coordination can be carried out by means of institutional mechanisms or be advanced by means of organizational networks.

Fourth, the supply of resources for social governance. Social governance is essentially a process of interest coordination, which includes not only the resolution of interest conflicts in micro-grassroots areas, but also the adjustment of interest pattern and the redistribution of resources in macro-global areas. Although the introduction of social capital, the application of market mechanism and the outsourcing of public services are important means of modern social governance and should be listed as the content of social governance innovation in China, the government, as the actual operator of the national absorption and authoritative distribution of social value, is undoubtedly still the main supplier of social resources. The ability of the government to distribute social resources fairly is an important indicator to measure the level of social governance.

All in all, the government is the "leader" and "maker" of the rules of social governance, the "coordinator" and "balancer" of the game of social interests, and the "promoter" and "server" of social public services. The government should actively cooperate with other social forces to achieve the good governance of society through dialogue and cooperation [7]. In fact, the degree of government intervention, the space reserved for social autonomy and the relationship between government and society in the governance structure need to be comprehensively considered according to the political system, social characteristics and development needs, governance habits and cultural traditions of different countries. The leading role of the government in the social structure is not only the need of the current social transformation, but also the result of the logical evolution of history itself.

\section{Construction of a Government Ruled by Law Is a Necessary Condition for Social Governance Innovation}

The leading role of the government in social governance may develop in two directions in the actual operation. First, it will exaggerate the action of the leading role. As such, the government will not decentralize some of its functions when absolutely necessary and maintain its monopoly or control position in some mature fields already operated well by society so as to suppress social vitality. For example, setting various unreasonable conditions for the development of social organizations, intervening strongly in the process of grass-roots autonomy, intentionally excluding or weakening public participation in social and public affairs, or even being crazy about creating various power rent-seeking opportunities. Second, it will exaggerate the inaction of the leading role. Consequently, the government will abandon its power when it does not have to, intentionally or unintentionally weaken its responsibility for social governance, which leads to the people's dissatisfaction with the reality, the accumulation of 
social injustice, and even the rise of various acts of violence, making social governance more difficult. For example, it adopts an ostrich policy towards market defects, growing public services and social conflicts, and different government departments prevaricate when encountering governance problems and responsibilities.

In fact, the role of government in the process of social governance innovation lies in the construction of administration ruled by law. The difference between the administrative government and the government ruled by law is the structural relationship between the government and society, as well as the basis of the structural relationship among different levels within the government, and the different choices of behavioral modes determined therefrom. The former relies on power resources and pursues the principle of supremacy of power, thus taking administrative order as the main way to execute government affairs, while the latter relies on legal rules and pursues the principle of being based on law, thus taking governance according to law as the main way to execute government affairs. Any government administrative function can not be executed without power, nor can it be executed without the way of administrative order. However, the administrative government absolutizes the power; the administrative order often becomes the embodiment of the subjective will of the leaders of the government departments rather than the will of the state; the power and responsibility are unbalanced, and the legal norms are only regarded as the alternative but not the only basis for executing the power. Such administrative acts, though highly efficient in execution, are easy to deceive the superior and become a kingdom by themselves, and are prone to be tyrannical and arrogant to the subordinate with absolute arbitrariness.

The experience of social governance shows that it is the society that determines the government and it is the government that serves the society, and the society in dynamic change will inevitably put forward new requirements for government reform. Only by standardizing the operation of administrative power with the rule of law and realizing the transformation of administrative government to the government ruled of law can we lead and guarantee the innovation of social governance and promote the the good governance of government. The essence of innovation in social governance should be the definition of government power through the rule of law to form a reasonable relationship between government and society. The legalization of social governance includes not only the legalization of people's participation in public affairs, but also the legalization of administrative actions, as well as the legalization of government reform, that is, the legalization of internal relations. Only by promoting the innovation of social governance with the thinking and methodology under the rule of low and giving full play to the leading and promoting role of the rule of law, can we overcome the inertia of power and correct the capriciousness of power. The construction of administration ruled by law includes: the government exercises its functions and powers in accordance with the law; the government provides services to the society and is responsible for the society in accordance with the law; and the government promotes the transformation of functions and the reform of the administrative system in accordance with the law. Therefore, the construction of government ruled by law involves the following two aspects: the legalization of the relations between the government and the society, and the legalization of the relations among different levels and departments within the government.

The government under the rule of law includes two basic meanings: one is to manage and supervise the government according to law; the other is to administrate the government according to law. The meaning of a society ruled by law is: the state manages all fields of society according to law; civil behavior should take law as the basic criterion and be regulated and restricted by law, which is the bottom line of civil behavior. [8]The bottom line of civic behavior. In the process of social governance innovation, the legalization of the relations between the government and society can be seen as the functional demand of social governance in the process of social transformation, including the limitation of power in a negative sense and responsibility in a positive sense, which is a scientific definition of the connotation of the leading role of the government in social governance. The legalization of relations among different levels and departments within the government can be seen as the structural guarantee of good social governance, including clear norms of power relations in static sense and smooth implementation of reform policies in dynamic sense, which is the prerequisite for the government to play a leading role in social governance. The leading role of the government is related to the success or failure of social governance in our country. Other participants in social governance determine that they can only represent the interests of some of the people in the society from their own nature, and the narrow scope of interests affects the realization of social common interests. [9]

\section{The Path Choice of Construction of Government Ruled by Law from the Perspective of Social Governance}

In the new era of socialism with Chinese characteristics, the legalization of social governance has been promoted to an unprecedented level. [10]The innovation of social governance and the construction of government ruled by law are mutually connected in theory and practice. For the innovation of social governance, the construction of government ruled by law is the key to dissolve the tension between the leading role of the government and the restriction of power, and to solve the problem of the dual identity of the government, so as to not only develop appropriate social space for the government, but also provide a strong organizational guarantee for its orderly advancement. For the construction of a government ruled by law, the innovation of social governance is not only the time adaptation and power accumulation at the historical level, but also the value orientation and connotation exploration at the normative level, as well as the horizon expansion and path 
setting at the methodological level, so as to answer the questions of why we would like to construct the government ruled by law, what kind of government ruled by law we would like to construct, and how we construct the government ruled by law.

The systematic innovation of social governance determines that the construction of government ruled by law must focus on regulating the relations between the government and society, and the internal relations within the government by adopting the practical path of "work in concert both inside and outside, work in connection from up to down" guided by the methodological principle of "integration". To be specific, not only should the state execute its power in demonstration, guidance, coordination and overall planning, but the local government and grassroots should also play their role consciously, so as to achieve the overall effect of the construction of government ruled by law; not only should the state give full play to its conscious role, but also the external promoting role of social forces should be paid attention to, so as to form a joint force in the construction ruled by law; not only should the legal norms and procedural requirements be operate strictly, but the culture of rule of law should also be cultivated flexibly to create a harmonious atmosphere, so as to form the comprehensive ability in constructing the government ruled by law. This practical way of thinking should be embodied in all aspects of the construction of a government ruled by law, and unified in the practice of government-led social governance innovation.

First, the system of social governance should be improved. In the organizational system of social governance, the government assumes the leading responsibility. Once these systems are established, they will also become an important part of the political ecological environment of the government ruled by law, which are not only the legal weapon for the society to protect its own rights and interests orderly and autonomously and reject improper influence of public power, but also the important basis for the government to restrict its power, assume its responsibility, and play its leading role correctly, thus being an indispensable basic work for the construction of the government ruled by law. Among them, the most important thing is to respect the procedural requirements of social governance. By improving people's understanding of procedural justice in terms of ideology and cognition, we can constantly exaggerate and create a cultural atmosphere of procedural rule of law, so as to improve social governance on the basis of concept innovation. [11] The improvement of the social governance system should follow the principle of "fair rights, fair opportunities and fair rules" embodied in the law, and focus on the following three aspects. First, the legislation in citizens' personal rights, property rights, basic political rights and other related fields should be strengthened to ensure the implementation of citizens' economic, cultural and social rights. Second, based on the new changes in society, the system of grass-roots autonomy and social non-governmental organizations should be further improved to create legal conditions for social self-management, self-organization and self-service. Third, the construction of network behavior system should be accelerated so as to guide the healthy development of network public sphere. Social organizations grow, forming a kind of self-governing and independent power, and using the power of social organizations to restrain or restrict the arbitrary exercise of political parties and government power. Mutual restraint and balance are also ways to promote the progress of the rule of law. [12]

Second, the role of the rule of law in the construction of a government ruled by law should be strengthened. The important sign of the transformation from administrative government to government ruled by law is the government reform and the legalization of the relationship within the government, which is the basic premise of social governance innovation to obtain stable space. This means that only by transforming the reform policies of the central government into legal norms with coercive efficiency, can we form the lasting power support for the construction of government under the rule of law, so as to effectively prevent the deviation of the government's leading role in social governance. Therefore, governments at all levels should take the initiative to adjust their administrative functions and powers in accordance with legal requirements and social actual needs. According to their functions, they should sort out and formulate lists of powers (items subject to administrative examination and approval) and responsibilities (public services), as well as operational flow charts of power operation and responsibility bearing. The list of government functions, powers and responsibilities, operational flow charts, legal norms and social basis shall be published to the public, and the process of administrative power operation shall be gradually made public on the Internet. The main responsibility of the government under the rule of law should be clarified, and the requirements of the construction of the government under the rule of law should be incorporated into the government performance appraisal system, and the accountability system should also be strengthened; the restriction and oversight of power within the government should be strengthened, so as to make administration in accordance with the law the focus of internal oversight.

Third, social forces should be guided actively into the practice of the construction of government ruled by law. The leading role of government is not only reflected in the process of innovation of social governance, but also in the process of the construction of government ruled by law. However, this does not mean that the role of society is not important. Social development is the fundamental driving force of innovation of social governance and the construction of the government ruled by law, and especially, the demand for social autonomy governance will evolve into a strong external pressure to regulate the operation of government power and promote the reform of social system and government. The people are the creators of social history and the main body of social practice, so it is easier for the people to find and find social problems, to understand the development degree of social problems, and to bring various influences to people and society. [13]More importantly, the society can also integrate into the operation of 
public power through political participation, and play a direct role in promoting the process of government reform. Social participation in the construction of the government ruled by law embodies not only the modern political value concept that government power is granted by society, but also the full and effective expression of society's own needs, thus forming a constructive force within the system, which can ensure the rationality of delimiting the boundary of government power and determining the degree and mode of intervention in social governance. Practice has proved that social organizations can effectively integrate and connect social public welfare resources and government public service resources. Only by truly playing the role of social organizations can we greatly promote the scientific and orderly development of social governance. [14]

Fourth, the cultivation of the cultural identity of government officials to the rule of law should be paid attention to. The rule of law culture is conducive to the formation and consolidation of the belief in the rule of law and the realization of social equity and justice. As a flexible means of restriction and regulation, the rule of law culture can be regarded as "soft power". [15] The authority of the rule of law originates from people's sincere belief in law. The construction of the government ruled by law can not be separated from the cultivation of the culture ruled by law. Only when government officials consciously recognize the legal norms, have reverence for the law, and keep in mind that the red line of the law cannot be crossed and the bottom line of the law cannot be touched, can the spirit of the rule of law be internalized into a habitual mode of administrative behavior. Cultural identity under the rule of law has its own internal mechanism: perceptual cognition is the beginning, knowledge acquisition is the basis, behavior implementation is the way, interests fit is the key, the cultivation of ideas is the result, and these aspects are all interrelated and interactive with each other. The government should strengthen the cooperation and interaction with the academic circles, integrate the latest academic achievements of the government under the rule of law into the content system of the education of the rule of law, help public servants to timely solve the legal confusion encountered in social governance, and help public servants to turn the initially formed perceptual cognition of the rule of law into a systematic and rational cognition. The government should also take the administration according to law as an important basis for rewards and punishments, closely link them with the vital interests of public officials, and create an atmosphere of the culture of rule of law.

\section{Conclusion}

In the construction of the rule of law government in our country, we should keep the leading position of the government and take the government as the leading to carry out social governance. At present, the innovation of social governance in China must strengthen the construction of the government under the rule of law. Only when the government changes from relying on the rule of man to relying on the rule of law can the mode of social governance be innovated. The Chinese government must strengthen the role of the rule of law in the construction of the government, cultivate the identification of the government staff with the rule of law culture, enhance the spirit of the rule of law, and introduce social forces to jointly promote the improvement of the social governance system.

\section{References}

[1] Wen Jun. innovation and mission of social governance in the new reform period. Shanghai urban management, NO. 1, 2015.

[2] Kong Fanbin. "The reproduction of publicity", Nanjing: Jiangsu People's Publishing House, 2012, PP. 61.

[3] Li Dan. Research on Social Governance Innovation led by the government. Leadership Science Forum, NO. 11, 2018.

[4] Ma Youle. Government under the rule of law: the key to the refinement of social governance. Theoretical guide, NO. 6, 2017.

[5] Xiao Jinming. Promoting the theoretical and practical innovation of legal society. Journal of law, NO. 8, 2017.

[6] James N. Rosenau. "Governance without Government", Jiangxi People's Publishing House, 2001, PP. 2.

[7] Ding Donghan. "Constructing Service-oriented Government from the Perspective of Meta-Governance Theory", Humanities \& Social Sciences Journal of Hainan University, NO. $5,2010$.

[8] Zhao Chuanjun. Deep thinking on the legalization of social governance. Foreign trade and economic cooperation, NO. 1, 2015 .

[9] Zhang Youliang, Shang Qiaoyan. The dilemma and way out of government leading in social governance. Journal of Social Sciences, Jiamusi University, NO. 2, 2018.

[10] Ren Fuying. How to realize the legalization of social governance. People's forum, NO. 2, 2019.

[11] Chen rongzhuo, Yan Huijuan. Social governance from the perspective of rule of law: regional practice and innovation path. Jianghan forum, NO. 12, 2013.

[12] Chen Jinzhao. The implication of the strategy of implementing the rule of law in China. Law and business research, NO. 3 2016.

[13] Wang Weiling. On the innovation of social governance in the new situation. Journal of Suzhou Institute of education, NO. 1, 2017.

[14] Wu Yumin: enhancing the ability of social autonomy in innovative social management, research on socialism, NO. 4, 2011.

[15] Wu Jinge. Multidimensional perspective of social governance by law. Journal of Kaifeng Institute of education, NO. 7, 2019. 